\title{
Antihypertensive effect of gomisin A from Schisandra chinensis on angiotensin II-induced hypertension via preservation of nitric oxide bioavailability
}

\author{
Ji Young Park ${ }^{1,3}$, Jung Wook Yun ${ }^{1,3}$, Young Whan $\mathrm{Choi}^{2}$, Jin Ung Bae ${ }^{1}$, Kyo Won Seo ${ }^{1}$, Seung Jin Lee ${ }^{1}$, \\ So Youn Park ${ }^{1}$, Ki Whan Hong ${ }^{1}$ and Chi Dae Kim ${ }^{1}$
}

Gomisin A (GA) is a small molecular weight lignan present in Schisandra chinensis, and has been demonstrated to have vasodilatory activity. In the present study, we investigated the effect of GA on blood pressure (BP) in angiotensin II (Ang II)induced hypertensive mice. C57/BL6 mice infused subcutaneously with Ang II ( 1 and $2 \mu \mathrm{g} \mathrm{kg}^{-1}$ per min for 2 weeks) showed an increase in BP with a decrease in nitric oxide (NO) metabolites in plasma, and a negative correlation between these two parameters was demonstrated. In the thoracic aorta from Ang II-induced hypertensive mice, a decrease in vascular NO that was accompanied by a diminution of phosphorylated endothelial nitric oxide synthase (eNOS), as well as by increased reactive oxygen species (ROS) production, was demonstrated. These alterations in BP, eNOS phosphorylation and ROS production in the vasculature of Ang II-treated mice were markedly and dose-dependently reversed by simultaneous administration of GA ( 2 and $10 \mu \mathrm{gg}^{-1}$ per $\mathrm{min}$ ). In addition, Ang II-induced ROS production in cultured vascular cells such as endothelial cells and vascular smooth muscle cells was markedly attenuated by GA. These results suggested that GA attenuated the increase in BP via preservation of vascular NO bioavailability not only by inhibiting ROS production but also by preventing the impairment of eNOS function in the vasculature of Ang II-induced hypertensive mice.

Hypertension Research (2012) 35, 928-934; doi:10.1038/hr.2012.50; published online 26 April 2012

Keywords: angiotensin II; gomisin A; nitric oxide; ROS

\section{INTRODUCTION}

An increase in arterial blood pressure (BP) is generally regarded as a major risk factor for heart attack and stroke. ${ }^{1}$ Dysfunctional endothelium, characterized by a reduced nitric oxide (NO) production, is recognized as an independent factor for an increase in arterial BP. ${ }^{2}$ It is well known that impairment in endothelial nitric oxide synthase (eNOS) activity has an important role in the pathogenesis of endothelial cell dysfunction. Previous studies indicate that eNOS is upregulated by post-translational modifications, such as Aktinduced phosphorylation. ${ }^{3-4}$ Thus, a decline in NO bioavailability may be caused by alterations in cellular signaling involved in eNOS phosphorylation as well as by an accelerated NO degradation by reactive oxygen species (ROS). ${ }^{5}$

An increasing body of evidence suggests novel roles for angiotensin II (Ang II) in regulating the balance between NO and ROS in the vasculature. $^{6-7}$ Ang II activates $\mathrm{NAD}(\mathrm{P}) \mathrm{H}$ oxidase and induces ROS generation in vascular smooth muscle cells, endothelial cells and intact arteries. ${ }^{8}$ An important source of ROS in endothelial and vascular smooth muscle cells is NADPH oxidase. ${ }^{9-10}$ Moreover, the strict cross talk between Ang II and NADPH oxidase was also confirmed by in vivo studies. ${ }^{8}$ Indeed, many of the consequences of Ang II exposure, including hypertension and vascular remodeling, are reportedly related to the formation of ROS. ${ }^{11-12}$

In traditional Korean herbal medicine, Schisandra chinensis (SC) has long been used for its antioxidant, tonic and sedative effects. It is also known to have potent antioxidative and anti-inflammatory effects. ${ }^{13-15}$ Recently, we demonstrated that gomisin A (GA) isolated from SC induced vasorelaxation in isolated rat thoracic aorta in endothelium-dependent and -independent manners, ${ }^{16-17}$ suggesting that GA might prevent the increase in arterial $\mathrm{BP}$, however, the effect of GA on BP in an animal model of hypertension has not been clarified.

In the present study, we evaluated the effect of continuous infusion of GA on the increase in arterial BP in Ang II-induced hypertensive mice. In addition, as GA prevented the loss of $\mathrm{NO}$ in isolated blood vessels from Ang II-induced hypertensive mice, we also investigated

${ }^{1}$ Department of Pharmacology, School of Medicine, and MRC for Ischemic Tissue Regeneration, Pusan National University, Gyeongnam, Republic of Korea and ${ }^{2}$ College of Natural Resources \& Life Sciences, Pusan National University, Gyeongnam, Republic of Korea

${ }^{3}$ These authors contributed equally to this work.

Correspondence: Professor CD Kim, Department of Pharmacology, School of Medicine, and MRC for Ischemic Tissue Regeneration, Pusan National University, Yangsan, Gyeongnam 626-870, Republic of Korea.

E-mail: chidkim@pusan.ac.kr

Received 2 November 2011; revised 14 February 2012; accepted 8 March 2012; published online 26 April 2012 
the possible mechanisms involved in GA-mediated preservation of NO bioavailability in the vasculature of Ang II-treated mice.

\section{METHODS}

\section{Plant collection and extraction of GA}

The fruits of SC were collected in September 2005 from Mungyeong, Korea. A voucher specimen (accession number SC-PDRL-1) was deposited in the Herbarium of Pusan National University. Pure GA was extracted from the dried fruits of SC, and identified by HPLC on a Phenomenex Luna C18 column (Phenomenex, Torrance, CA, USA, $150 \times 4.6 \mathrm{~mm}$ I.D.; $5 \mu \mathrm{m}$ particle size). The chemical structure of GA was verified by liquid chromatographymass spectrometry (LC-MS, Bruker BioApex FT mass spectrometer, Bruker, Billerica, MA, USA) and NMR analysis (Bruker DRX 400 spectrometer, Bruker, Pullman, WA, USA). The solid form of GA (MW=416.46) was dissolved in DMSO, and subsequently diluted in media in all experiments.

\section{Cell culture}

The mouse aorta was dissected, cut into $1-2 \mathrm{~mm}^{2}$ segments, and then placed as explants in cell culture dishes containing DMEM (Gibco BRL, Grand Island, NY, USA) with $10 \%$ fetal bovine serum. VSMC purity was determined by staining with smooth muscle-specific actin monoclonal antibodies (SigmaAldrich Co., St Louis, MO, USA).

Human coronary artery endothelial cells and human umbilical vein endothelial cells were obtained from Lonza (Walkersville, MD, USA). Cells were cultured in endothelial growth medium-2 (EGM-2 MV, Lonza). Cells between passages 4 and 6 were used in the present study.

\section{Animals and experimental design}

All animal procedures were conducted in accordance with the Animal Care Guidelines of Pusan National University Institutional Animal Care and Use Committee. Male C57BL/6 mice (20-25g) were implanted with a subcutaneous osmotic minipump (Alzet model 1002, Alza Corp., Vacaville, CA, USA) filled with either Ang II (Sigma Chemical Co., St Louis, MO, USA) or $\mathrm{NaCl}$ (sham-treated mice) for 14 days. The average Ang II infusion rate was 1 and $2 \mu \mathrm{gg}^{-1}$ per min. To determine the effects of GA on Ang II-induced hypertension, some animals were treated concomitantly with a subcutaneously implanted osmotic minipump containing GA ( 2 or $10 \mu \mathrm{gg}^{-1}$ per min) for 14 days. The systolic BP was measured by tail cuff plethysmography with the aid of a computerized system (BP2000 Blood Pressure Analysis System, Visitech Systems, Apex, NC, USA).

\section{Measurement of NO metabolites in plasma}

Accumulation of nitrate and nitrite, the end products of $\mathrm{NO}$ metabolism used as indices of NOS activity, was measured in plasma as previously described. ${ }^{18}$ In brief, plasma samples were deproteinized by ultrafiltration using centrifugal concentrators (Nanosep, Pall Filtron, Northborough, MA, USA). The supernatant was reacted with Griess solution (Promega, Madison, WI, USA) for $15 \mathrm{~min}$. The absorbance of samples was measured at $540 \mathrm{~nm}$ on Emax ELISA microplate reader using SoftMax Pro Software (Bio-Tek Instruments Inc., Winooski, VT, USA).

\section{Measurement of vascular concentration of NO}

At the end of the study period, the mice were anesthetized with chloral hydrate $\left(450 \mathrm{mg} \mathrm{kg}^{-1}\right.$, i.p.). The thoracic aorta was rapidly excised, and dissected from adhering connective and adipose tissue. For the fluorometric experiments, the aortic rings ( $3 \mathrm{~mm}$ in width) were incubated for $2 \mathrm{~h}$ in the dark in Krebs' buffer containing $10 \mu \mathrm{M}$ DAF-FM DA (Molecular Probes, Karlsruhe, Germany), a fluorescent NO-sensitive dye. The aortic rings were rapidly removed and frozen at $-20^{\circ} \mathrm{C}$. Aortic rings were cut into $10 \mu \mathrm{m}$-thick sections in a microtome (HM550, MICROM GmbH, Walldorf, Germany) and placed onto microscope slides without any mounting medium or coverslip. Fluorescence was detected using an Axiovert 200 fluorescence microscope (Carl Zeiss, Oberkochem, Germany).

\section{Measurement of ROS}

Vascular superoxide anion production was measured using lucigenin-enhanced chemiluminescence method. The aortic ring segments were cryocut into $3 \mu \mathrm{m}$ thick sections and mounted on gelatin chromalumin-coated slides. The sections were incubated for $30 \mathrm{~min}$ with $5 \mu \mathrm{M}$ DHE. After the sections were washed two times with PBS, fluorescence of DHE was detected using an Axiovert 200 fluorescence microscope (Carl Zeiss).

Intracellular ROS was measured using DCFH-DA (Molecular Probes), which can then react with ROS to form highly fluorescent DCF. ${ }^{19}$ The vascular smooth muscle cells and endothelial cells grown in 12-well plates were incubated with $10 \mu \mathrm{m}$ DCFH-DA for $30 \mathrm{~min}$. After incubation, the cells were washed with PBS, and then the fluorescence of DCFH-DA was detected using an Axiovert 200 fluorescence microscope (Carl Zeiss).

\section{Western blot analysis for eNOS and phosphorylated-eNOS}

Mouse aortic tissue was homogenized and equal amounts $(20 \mu \mathrm{g})$ of protein per sample were separated on $8 \%$ SDS-PAGE gels and subsequently transferred to polyvinylidene fluoride membrane. After blocking with 5\% skim milk, the membranes were incubated with purified mouse anti-eNOS (1:1000, BD Biosciences) and purified mouse anti-phospho Ser1177 eNOS (1:1000, BD Biosciences) at $4{ }^{\circ} \mathrm{C}$ overnight. The membranes were then washed and further incubated with secondary antibody, and the bands were visualized by the addition of enhanced chemiluminescence detection reagents.

\section{Statistics}

The results were expressed as mean \pm s.e.m. Statistical significance of difference between groups was analyzed by one-way analysis of variance (ANOVA) followed by Tukey's multiple comparison test using statistical software (Prism, version 3.03; GraphPad Software Inc., San Diego, CA, USA). $P<0.05$ was regarded as significant.

\section{RESULTS}

Characterization of Ang II-induced hypertension

At the beginning of the experiment, BP of control and Ang II ( 1 and $2 \mu \mathrm{g} \mathrm{kg}$ per $\mathrm{min}$ )-treated mice were $93.5 \pm 4.1,98.1 \pm 3.0$ and $91.6 \pm 4.1 \mathrm{~mm} \mathrm{Hg}$, respectively. While the BP of control mice remained constant throughout the period of investigation, the $\mathrm{BP}$ of Ang II ( 1 and $2 \mu \mathrm{g} \mathrm{kg}^{-1}$ per min)-treated mice started to increase at day 4 and peaked at day 6 of the experimental period $(139.9 \pm 5.7 \mathrm{~mm} \mathrm{Hg})$, and then the elevated BP was sustained at a high level for 14 days. The effects of Ang II at $2 \mu \mathrm{g} \mathrm{kg}^{-1}$ per min on $\mathrm{BP}$ were more prominent and stable than those at $1 \mu \mathrm{g} \mathrm{kg}^{-1}$ per min (Figure 1). However, there were no significant differences between groups with regard to heart rates $(517 \pm 20$ beats per min in control group, $544 \pm 59$ and $546 \pm 29$ beats per min in Ang II 1 and $2 \mu \mathrm{g} \mathrm{kg}^{-1}$ per min-treated groups, respectively).

\section{Role of Ang II on vascular NO production}

In good agreement with previous reports in which Ang II inhibited eNOS activity, ${ }^{20-21} \mathrm{NO}$ concentration was diminished in aortic tissues from Ang II-treated mice compared with those from control mice (Figure 2a). Likewise, the concentration of nitrate/nitrite, metabolites of NO, was also diminished in the plasma of Ang II-treated mice in a dose-dependent manner (Figure $2 \mathrm{~b}$ ). When the relationship between systolic BP and plasma concentration of nitrites was examined in each mouse, systolic BP was found to be negatively correlated with plasma concentration of NO metabolites (Figure 2c). This suggests that the elevation in BP in Ang II-treated mice may be a consequence of reduction in the bioavailability of NO.

\section{Antihypertensive effect of GA on Ang II-induced hypertension} As the effects of Ang II at $2 \mu \mathrm{g} \mathrm{kg}^{-1}$ per min on BP were more prominent and stable than those at $1 \mu \mathrm{g} \mathrm{kg}^{-1}$ per min, the following 
experiments were performed in mice treated with Ang II at $2 \mu \mathrm{g} \mathrm{kg}^{-1}$ per min. As shown in Figure 3, concomitant treatment with GA ( 2 and $10 \mu \mathrm{g} \mathrm{kg}^{-1}$ per $\mathrm{min}$ ) in Ang II-treated mice significantly attenuated the increase in BP in a dose-dependent manner. However, there were no significant differences between groups with regard to heart rates $(546 \pm 29$ beats per min in control group; $532 \pm 47$ and $542 \pm 67$ beats per min in GA 2 and $10 \mu \mathrm{g} \mathrm{kg}^{-1}$ per min-treated groups, respectively).

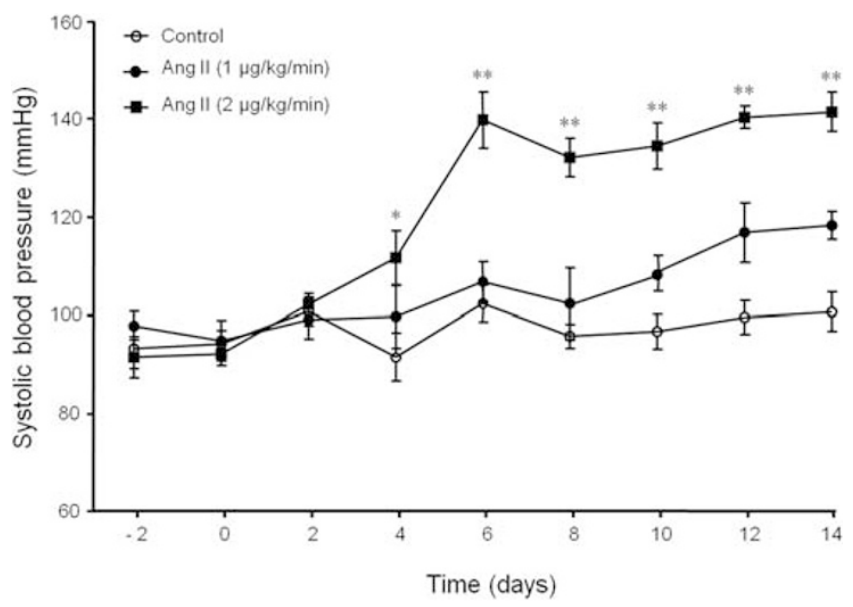

Figure 1 Effect of Ang II infusion on systolic blood pressure. Time course of systolic blood pressure in C57BL/6 mice treated with a subcutaneous osmotic minipump filled with Ang II ( 1 and $2 \mu \mathrm{g} \mathrm{kg}^{-1}$ per min) for 14 days. Data were expressed as mean \pm s.e.m. from 5-7 independent experiments. ${ }^{*} P<0.05,{ }^{* *} P<0.01$ vs. corresponding value in control.
Effect of GA on impaired NO production in Ang II-treated mice Vascular NO production as assayed with DAF-FM DA was markedly reduced in Ang II-infused animals compared with controls. With simultaneous chronic administration of GA (2 and $10 \mu \mathrm{g} \mathrm{kg}^{-1}$ per $\mathrm{min}$ ) in Ang II-induced hypertensive mice, the diminished NO concentration in isolated aorta from Ang II-treated mice was restored in a dose-dependent manner (Figure 4a). In line with vascular production of $\mathrm{NO}$, the decreased plasma concentration of $\mathrm{NO}$

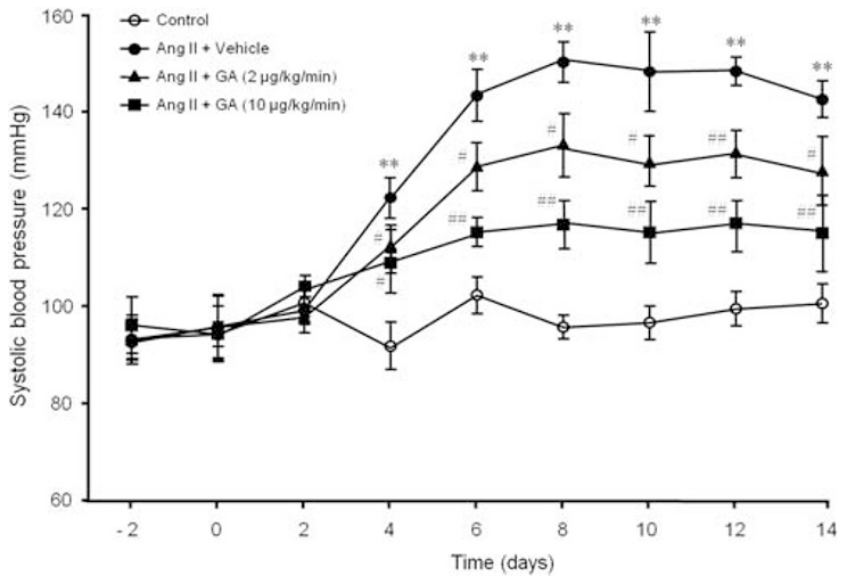

Figure 3 Preventive effect of GA on Ang II-induced hypertension. Time course of systolic blood pressure in Ang II-induced hypertensive mice treated with various concentrations of GA. Data are expressed as mean \pm s.e.m. from $7-13$ independent experiments. ${ }^{* *} P<0.01$ vs. corresponding value in control. ${ }^{\#} P<0.05$; ${ }^{\#} P<0.01$ vs. corresponding value in vehicle group.
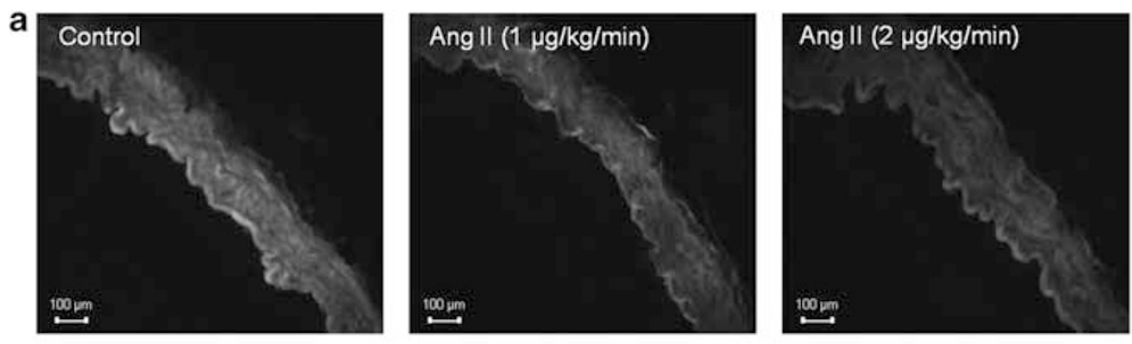

b

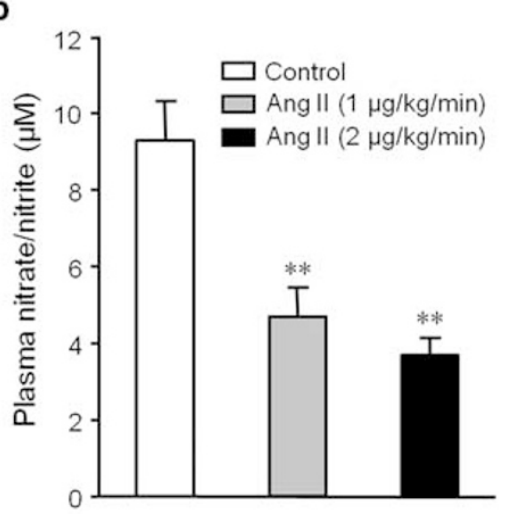

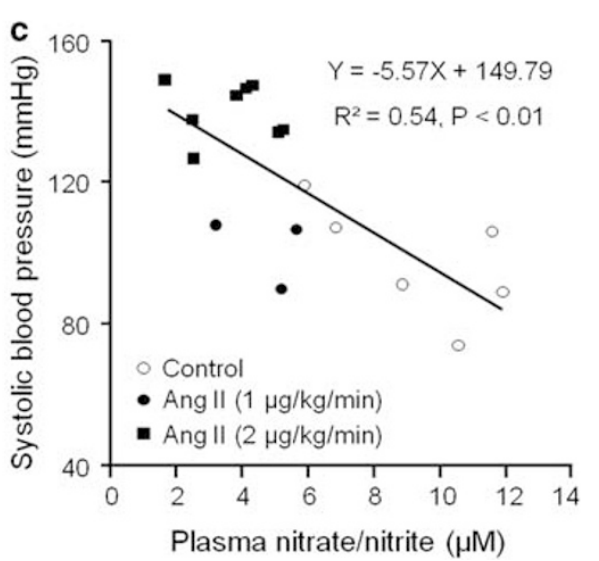

Figure 2 Effect of Ang II infusion on NO production. (a) Vascular NO production in aortic segments from control and Ang II-treated mice were measured by DAF2-FM staining. Photographs are representative of five independent experiments. (b) Plasma concentration of NO metabolites as an index for plasma NO concentration from control and Ang II-treated mice was measured by Griess reagent. Data are expressed as mean \pm s.em. from 4-7 independent experiments. ${ }^{* *} P<0.01$ vs. control. (c) Interaction between blood pressure and plasma nitrate/nitrite concentration in each mouse shows a negative correlation. A full color version of this figure is available at the Hypertension Research journal online. 
a
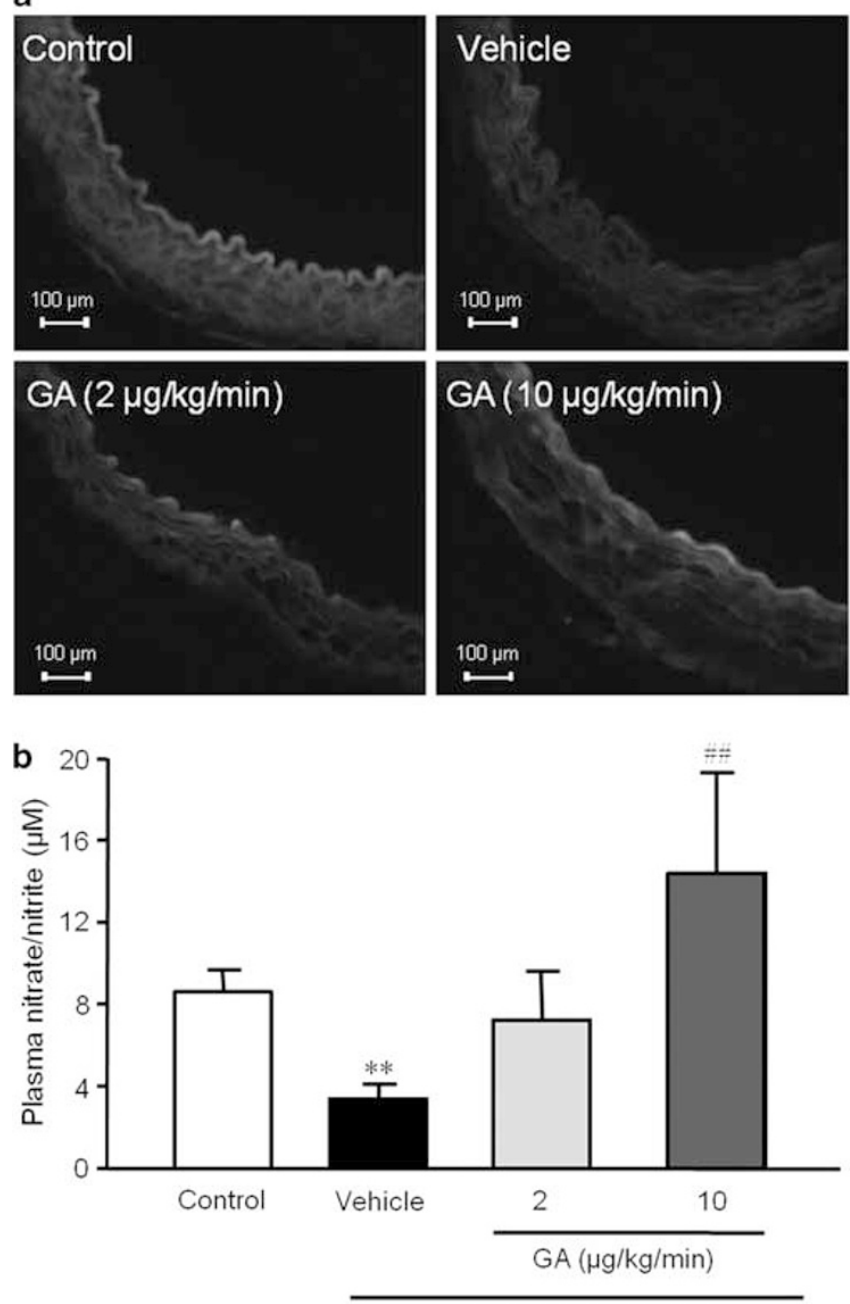

Ang II $(2 \mu \mathrm{g} / \mathrm{kg} / \mathrm{min})$

Figure 4 Effect of GA on impaired NO production in Ang II-treated mice. (a) Representative photographs of the preservation of NO production by GA in aortic tissues from Ang II-treated mice $(n=4)$. (b) The decreased plasma concentration of NO metabolites in Ang II-treated mice was significantly preserved by simultaneous chronic administration of GA (2 and $10 \mu \mathrm{kg}^{-1}$ per min). Data were expressed as mean \pm s.e.m. from 4-7 independent experiments. ${ }^{* *} P<0.01$ vs. control. ${ }^{\#} P<0.01$ vs. vehicle. A full color version of this figure is available at the Hypertension Research journal online.

metabolites in Ang II-treated mice was also significantly preserved by GA treatment (2 and $10 \mu \mathrm{g} \mathrm{kg}^{-1}$ per min) (Figure $4 \mathrm{~b}$ ).

Effect of GA on impaired eNOS activity in Ang II-treated mice Phosphorylation of eNOS at Ser1177 enhances eNOS activity. ${ }^{22}$ Thus, to assess the involvement of Ang II in the regulation of eNOS activity, we studied the effects of Ang II on the level of eNOS and phosphorylated-eNOS protein expression in aortic tissues from control and Ang II-treated mice. As shown in Figures $5 a$ and b, the expression level of phosphorylated-eNOS at Ser1177, but not eNOS expression, was markedly diminished in aortic tissue from Ang IItreated mice as compared with those from control mice. This attenuation in eNOS phosphorylation was inhibited by simultaneous treatment with GA in a dose-dependent manner.
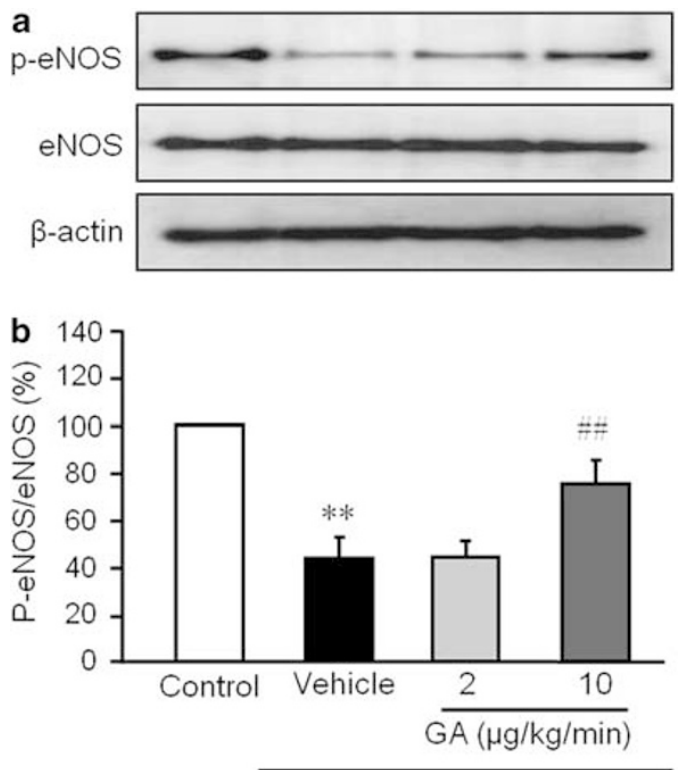

Ang II $(2 \mu \mathrm{g} / \mathrm{kg} / \mathrm{min})$

Figure 5 Effect of GA on impaired eNOS phosphorylation at Ser1177 in Ang II-treated mice. (a) Levels of phosphorylated eNOS (p-eNOS) at Ser1177, eNOS and $\beta$-actin protein were determined by western blot analysis. One representative blot out of six independent experiments is shown. (b) Each bar represents mean \pm s.e.m. from 4-6 independent experiments. ${ }^{* *} P<0.01$ vs. control. ${ }^{\#} P<0.01$ vs. vehicle.

\section{Effects of GA on Ang II-enhanced ROS production}

Ang II is known as a regulatory factor in vascular oxidation-reduction signaling to enhance superoxide production. ${ }^{9}$ Likewise, ROS production as measured by DHE was significantly increased in isolated aorta from Ang II-treated mice. The increased ROS production by Ang II was markedly attenuated in the aortic tissues from Ang II-treated mice with simultaneous treatment of GA (Figure 6a). Likewise, when vascular cells such as vascular smooth muscle cell and endothelial cells were exposed to Ang II $(1-10 \mu \mathrm{M})$ for $24 \mathrm{~h}$, ROS production in cells was gradually increased in a concentration-dependent manner (data not shown). The Ang II $(10 \mu \mathrm{M})$-induced increase in ROS production in cultured vascular cells was also markedly attenuated by pretreatment with GA $(1-10 \mu \mathrm{M})$ in a dose-dependent manner (Figure 6b).

\section{DISCUSSION}

The present study provides evidence that increased arterial BP in mice infused subcutaneously with Ang II was markedly attenuated by chronic administration of GA. The beneficial effects of GA on Ang IIinduced hypertension were associated with preservation of NO bioavailability in the vasculature. Moreover, GA treatment in this study was started at the prehypertensive stage, suggesting that GA had a prophylactic effect against the development of hypertension induced by Ang II.

Disruption of the NO pathway by L-NAME was demonstrated by reduced plasma nitrate/nitrite levels. ${ }^{23}$ Similarly, long-term treatment with Ang II also resulted in a significant reduction in the acetylcholine-induced increase in plasma NO concentration in rabbits. ${ }^{24}$ In the Ang II-infused rat model by Mollnau et al. ${ }^{25}$ showed that NO in the aortic segments was markedly reduced. In line with these previous studies, in mice infused subcutaneously with Ang II, we also found an increase in arterial BP with a decrease in NO 
a

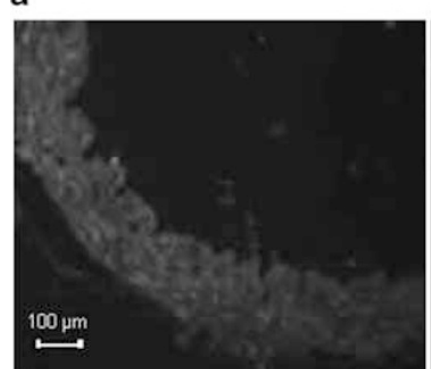

Control

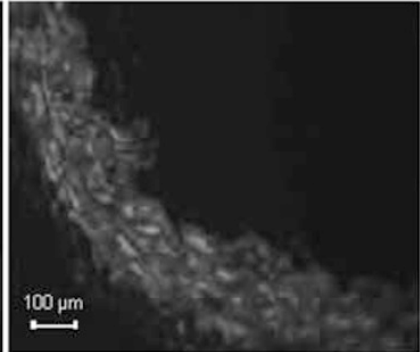

Vehicle

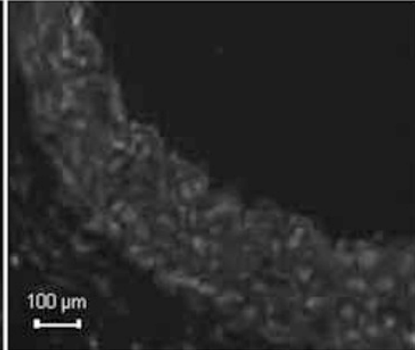

$\mathrm{GA}(2 \mu \mathrm{g} / \mathrm{kg} / \mathrm{min})$

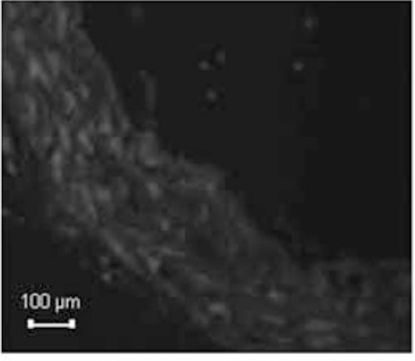

$\mathrm{GA}(10 \mu \mathrm{g} / \mathrm{kg} / \mathrm{min})$

Ang II $(2 \mu \mathrm{g} / \mathrm{kg} / \mathrm{min})$

b
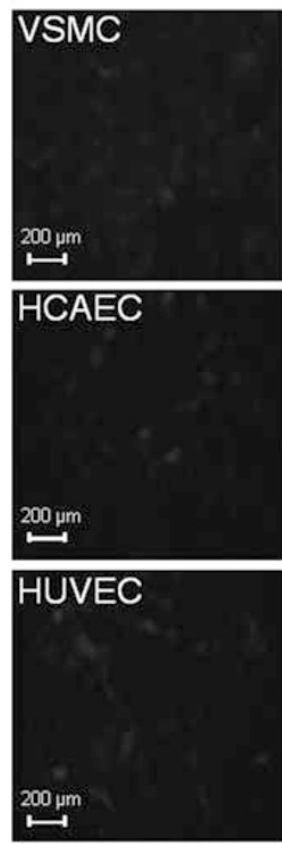

Control
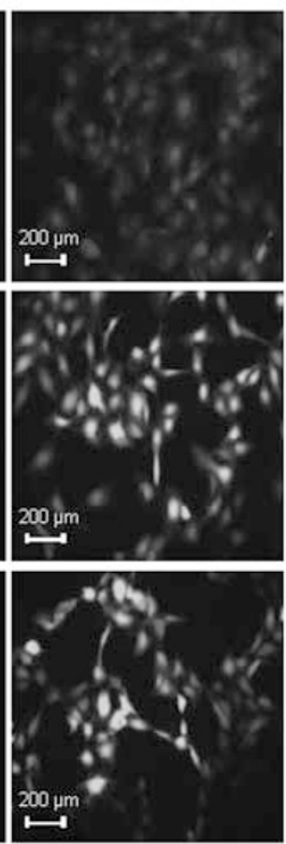

Vehicle
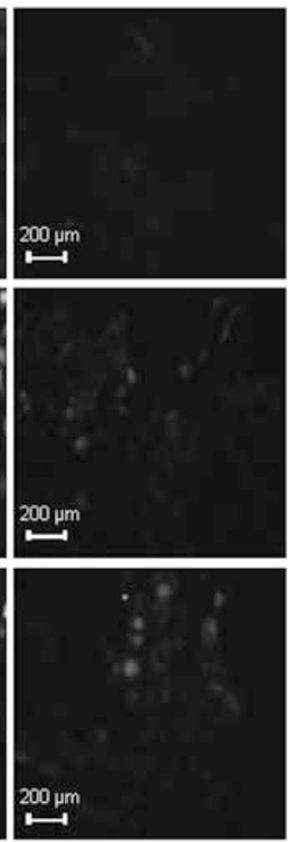

NAC
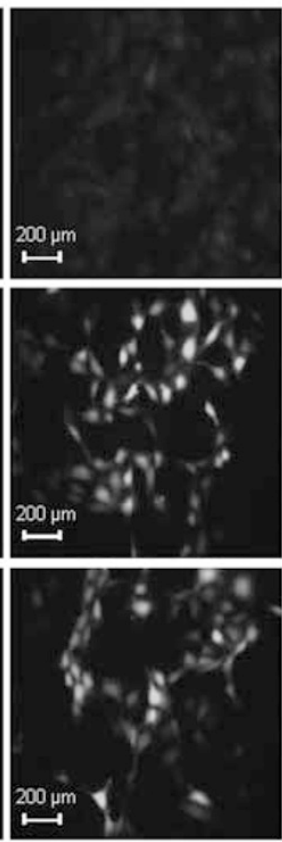

$\mathrm{GA}(1 \mu \mathrm{M})$
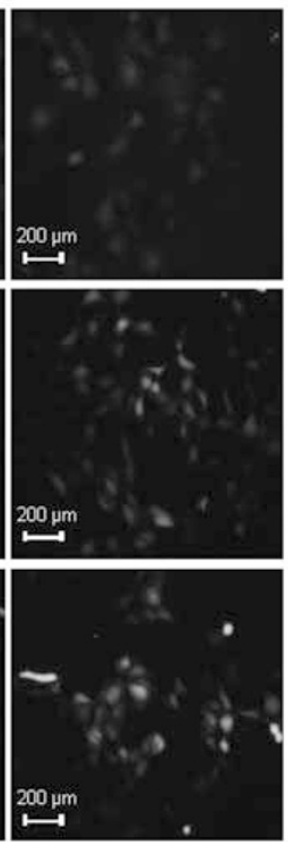

$\mathrm{GA}(3 \mu \mathrm{M})$
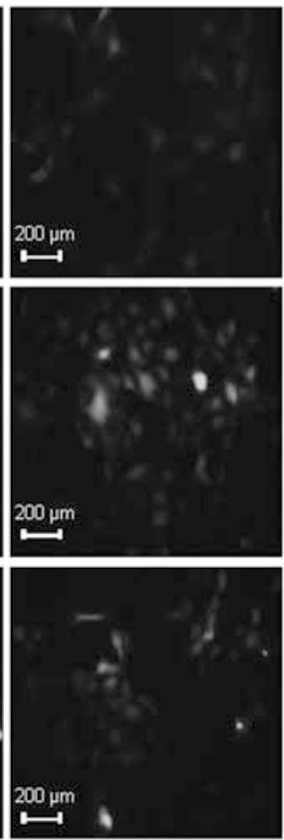

$\mathrm{GA}(10 \mu \mathrm{M})$

Ang $\|(10 \mu \mathrm{M})$

Figure 6 Effects of GA on Ang II-enhanced ROS production. (a) Representative photographs of ROS production as measured by DHE in aortic tissues from control, Ang II-treated mice without or with simultaneous treatment of GA $(n=5)$. (b) Vascular smooth muscle cells (VSMC), human coronary artery endothelial cell (HCAEC) and umbilical vein endothelial cell (HUVEC) were exposed to Ang II (10 $\mu \mathrm{m})$ for $24 \mathrm{~h}$, and then ROS production in cells was determined using DCF fluorescence. Photographs are representative of 5-6 experiments. A full color version of this figure is available at the Hypertension Research journal online.

metabolites in plasma, and a negative correlation between these two parameters. Thus, the dysfunctional endothelium, characterized by less production of $\mathrm{NO}$ as well as a decrease in NO bioavailability, appeared to lead to an increase in arterial BP in Ang II-infused mice.

A decline in NO bioavailability may be caused by alterations in cellular signaling involved in eNOS activation or by accelerated NO degradation by ROS. ${ }^{26}$ Our study showed that the decreased plasma concentration of $\mathrm{NO}$ metabolites in Ang II-treated mice was accompanied by diminished NO concentration in the aortic segments, suggesting a potential relationship between these two parameters. Moreover, the decreased level of NO in the vasculature might result from a decrease in NO synthesis by inhibition of eNOS activity or an increase in NO inactivation by enhanced vascular production of ROS.
To determine the involvement of Ang II in the regulation of eNOS activity, we studied the effects of Ang II on the level of eNOS and phosphorylated-eNOS protein expression in aortic tissues from control and Ang II-treated mice. In the segments of aorta isolated from mice treated with Ang II, a clear impairment in endothelial function was observed; however, eNOS expression was unaltered by Ang II treatment. ${ }^{27}$ In line with this report, our present results showed that expression level of phosphorylated-eNOS at Ser1177, but not eNOS expression, was markedly diminished in the aortic tissue from Ang II-treated mice compared with those from control mice. Thus, it was suggested that the impaired vascular production of NO might be partially involved in the decrease in NO bioavailability in Ang II-treated mice, subsequently leading to an increase in arterial BP. 
Many of the consequences of Ang II exposure, including hypertension and vascular remodeling, are reportedly related to ROS formation as a consequence of the activation of NADPH oxidases. ${ }^{11,28}$ Sachse and Wolf ${ }^{29}$ also provide evidence that Ang II stimulates intracellular formation of superoxide by upregulating subunits of the membrane-bound $\mathrm{NAD}(\mathrm{P}) \mathrm{H}$ oxidase and by facilitating assembly of subunits. In endothelial cells, Ang II activates mainly the Nox2 (gp91phox) and Nox4 subunits, and genetic disruption of Nox2 prevents the endothelial dysfunction observed in a high-renin model of hypertension. ${ }^{30}$ We therefore assessed ROS production in the vasculature isolated from Ang II-infused mice. Our present study clearly showed that ROS production in the aortic tissue from Ang IItreated mice was markedly increased. Moreover, in an in vitro study using VSMC and endothelial cells to determine the cellular source for Ang II-induced ROS generation, Ang II enhanced ROS generation in endothelial cells as well as in VSMC. Thus, it was suggested that hypertension caused by Ang II was mediated in part via a decrease in NO bioavailability by an increased production of ROS in the vasculature.

Traditionally, SC has been used as a Korean herbal medicine for its antioxidant, antitussive, tonic and sedative effects. SC fruits contain a variety of pharmacologically active lignans. GA and the major bioactive compounds are lignans with a dibenzocyclooctadiene skeleton. ${ }^{15,31-32}$ We recently showed that GA induced vasorelaxation in isolated rat thoracic aorta in an endothelium-dependent and -independent manner. ${ }^{16}$ Moreover, GA enhanced NO production by activation of eNOS in human coronary endothelial cells. ${ }^{17}$ Our previous reports describing a pivotal role of GA in vascular relaxation ${ }^{16-17}$ suggest that GA might have a potential role in the prevention of hypertension induced by various causes.

In the present study, chronic administration of Ang II into mice caused an increase in arterial BP with a diminished plasma concentration of NO metabolites, which was prevented by continuous infusion of GA. The effect of GA on NO bioavailability in Ang IIinfused mice might result from its preventive roles on impaired NO synthesis or increased NO inactivation by ROS. To determine the role of GA in NO synthesis, the effect of GA on the regulation of eNOS activity was investigated. The present study showed that GA attenuated the decrease in phosphorylated-eNOS (Ser1177) expression, leading to restoration of diminished plasma nitrate/nitrite levels. In our previous study, GA rapidly stimulated NO production and eNOS activation via enhanced eNOS translocation with little effect on the expression of both total eNOS and phosphorylated-eNOS protein. ${ }^{17}$ Likewise, the level of eNOS expression in the endothelial layer of the thoracic aorta from Ang II-treated mice was neither decreased compared with that in control nor affected by GA treatment. Interestingly, although GA did not enhance eNOS phosphorylation in endothelial cells in our previous study, ${ }^{17}$ our present study showed that the diminished level of phosphorylated-eNOS in Ang II-treated mice was instead markedly preserved in mice treated with GA. This indicates that GA might have a preventive role in Ang II-induced impairment of eNOS phosphorylation without affecting eNOS phosphorylation in the resting state. However, further experiments are necessary to determine the effect of GA on the cross-talk between Ang II and eNOS function.

Moreover, the increased ROS production in isolated aorta from Ang II-treated mice was markedly attenuated in the aortic tissues from Ang II-treated mice co-treated with GA. In addition, in agreement with previous studies in which Ang II enhanced ROS production in endothelial cells and vascular smooth muscle cells, ${ }^{33-34}$ this study also showed that Ang II increased ROS in vascular cells.
In line with the results from the in vivo study, Ang II-induced ROS production in cultured vascular cells was also markedly attenuated by pretreatment with GA. Recently, it was reported that treatment with antioxidants blunted the increase in BP caused by Ang II. ${ }^{23,35}$ Likewise, the results of our present study suggested that the antioxidative property-related protection against ROS-mediated degradation of NO in the vasculature may contribute at least partly to the antihypertensive effect of GA.

In conclusion, chronic administration of GA had an antihypertensive effect in Ang II-induced hypertensive mice. Its beneficial effects on NO bioavailability, which are mediated by preservation of vascular $\mathrm{NO}$, seem to be related to the antihypertensive activity. Based on these results, it was suggested that GA attenuated the increase in arterial BP via preservation of vascular NO bioavailability not only by inhibiting ROS production but also by preventing the impairment of eNOS function in the vasculature of Ang II-induced hypertensive mice.

\section{CONFLICT OF INTEREST}

The authors declare no conflict of interest.

\section{ACKNOWLEDGEMENTS}

This study was supported by the MRC Program of the MEST/KOSEF (20050049477), Bio-industry Technology Development Program and Ministry for Food, Agriculture, Forestry and Fisheries, Republic of Korea (311054-03-1HD120).

1 Nguelefack TB, Dongmo AB, Dimo T, Kamanyi A. Phytopharmacology of some medicinal plants used in Cameroonian traditional medicine to handle cardiovascular diseases. In Anna Capasso (ed) Recent Developments in Medicinal Plant Research, 2007, pp 147-167. ISBN 978-81-308-0160-5.

2 Davignon J, Ganz P. Role of endothelial dysfunction in atherosclerosis. Circulation 2004; 109: III27-III32.

3 Fulton D, Gratton JP, Sessa WC. Post-translational control of endothelial nitric oxide synthase: why isn't calcium/calmodulin enough? J Pharmacol Exp Ther 2001; 299: 818-824.

4 Venema RC. Post-translational mechanisms of endothelial nitric oxide synthase regulation by bradykinin. Int Immunopharmacol 2002; 2: 1755-1762.

5 Schulz E, Jansen T, Wenzel P, Daiber A, Münzel T. Nitric oxide, tetrahydrobiopterin, oxidative stress, and endothelial dysfunction in hypertension. Antioxid Redox Signal 2008; 10: 1115-1126.

6 Watanabe T, Barker TA, Berk BC. Angiotensin II and the endothelium: diverse signals and effects. Hypertension 2005; 45: 163-169.

7 Nakashima H, Suzuki H, Ohtsu H, Chao JY, Utsunomiya H, Frank GD, Equchi S. Angiotensin II regulates vascular and endothelial dysfunction: recent topics of angiotensin II type-1 receptor signaling in the vasculature. Curr Vasc Pharmacol 2006; 4: 67-78.

8 Virdis A, Duranti E, Taddei S. Oxidative stress and vascular damage in hypertension: role of angiotensin II. Int J Hypertens 2011; 2011: 916310.

9 Griendling KK, Minieri CA, Ollerenshaw JD, Alexander RW. Angiotensin II stimulates $\mathrm{NADH}$ and NADPH oxidase activity in cultured vascular smooth muscle cells. Circ Res 1994; 74: 1141-1148.

10 Somers MJ, Mavromatis K, Galis ZS, Harrison DG. Vascular superoxide production and vasomotor function in hypertension induced by deoxycorticosterone acetate-salt. Circulation 2000; 101: 1722-1728.

11 Garrido AM, Griendling KK. NADPH oxidases and angiotensin II receptor signaling. Mol Cell Endocrinol 2009; 302: 148-158.

12 Murdoch CE, Alom-Ruiz SP, Wang M, Zhang M, Walke S, Yu B, Breser A, Shah AM. Role of endothelial Nox2 NADPH oxidase in angiotensin Il-induced hypertension and vasomotor dysfunction. Basic Res Cardiol 2011; 106: 527-538.

13 Chen DF, Zhang SX, Xie L, Xie JX, Chen K, Kashiwada Y, Zhou BN, Wang P, Cosentino LM, Lee KH. Anti-AIDS agents-XXVI. Structure-activity correlations of gomisin-G-related anti-HIV lignans from Kadsura interior and of related synthetic analogues. Bioorg Med Chem 1997; 5: 1715-1723.

14 Chiu PY, Mak DH, Poon MK, Ko KM. In vivo antioxidant action of a lignan-enriched extract of schisandra fruit and an anthraquinone-containing extract of polygonum root in comparison with schisandrin B and emodin. Planta Med 2002; 68: 951-956.

15 Choi YW, Takamatsu S, Khan SI, Srinivas PV, Ferreira D, Zhao J, Khan IA. Schisandrene, a dibenzocyclooctadiene lignan from Schisandra chinensis: structureantioxidant activity relationships of dibenzocyclooctadiene lignans. J Nat Prod 2006; 69: 356-359. 
16 Park JY, Lee SJ, Yun MR, Seo KW, Bae SS, Park JW, Lee YJ, Shin W., Choi YW, Kim CD. Gomisin A from Schisandra chinensis induces endothelium-dependent and direct relaxation in rat thoracic aorta. Planta Med 2007; 73: 1537-1542.

17 Park JY, Shin HK, Choi YW, Lee YJ, Bae SS, Han J, Kim CD. Gomisin A induces $\mathrm{Ca}^{2+}$-dependent activation of eNOS in human coronary artery endothelial cells. $J$ Ethnopharmacol 2009; 125: 291-296.

18 Kukongviriyapan V, Somparn N, Senggunprai L, Prawan A, Kukongviriyapan U, Jetsrisuparb A. Endothelial dysfunction and oxidant status in pediatric patients with hemoglobin E-bata thalassemia. Pediatr Cardiol 2008; 29: 130-135.

19 Amer J, Goldfarb A, Fibach E. Flow cytometric measurement of reactive oxygen species production by normal and thalassaemic red blood cells. Eur J Haematol 2003; 70: 84-90.

20 Lin LY, Lin CY, Su TC, Liau CS. Angiotensin II-induced apoptosis in human endothelial cells is inhibited by adiponectin through restoration of the association between endothelial nitric oxide synthase and heat shock protein 90. FEBS Lett 2004; 574: $106-110$.

21 Marrero MB, Venema VJ, Ju H, He H, Liang H, Caldwell RB, Venema RC. Endothelial nitric oxide synthase interactions with G-protein-coupled receptors. Biochem J 1999, 343: 335-340.

22 Sessa WC. eNOS at a glance. J Cell Sci 2004; 117: 2427-2429.

23 Nakmareong S, Kukongviriyapan U, Pakdeechote P, Donpunha W, Kukongviriyapan V, Kongyingyoes B, Sompamit K, Phisalaphong C. Antioxidant and vascular protective effects of curcumin and tetrahydrocurcumin in rats with L-NAME-induced hypertension. Naunyn Schmiedebergs Arch Pharmacol 2011; 383: 519-529.

24 Imanishi T, Kobayashi K, Kuroi A, Mochizuki S, Goto M, Yoshida K, Akasaka T. Effects of angiotensin II on NO bioavailability evaluated using a catheter-type NO sensor. Hypertension 2006; 48: 1058-1065.

25 Mollnau H, Wendt M, Szocs K, Lassegue B, Schulz E, Oelze M, Li H, Bodenschatz M, August M, Kleschyov AL, Tsilimingas N, Walter U, Forstermann U, Meinertz T, Griendling K, Munzel T. Effects of angiotensin II on the expression and function of $\mathrm{NAD}(\mathrm{P}) \mathrm{H}$ oxidase and components of nitric oxide/cGMP signaling. Circ Res 2002; 90 e58-e65.

26 Cai H, Harrison DG. Endothelial dysfunction in cardiovascular diseases the role of oxidant stress. Circ Res 2000; 87: 840-844.
27 Loot AE, Schreiber JG, Fisslthaler B. Angiotensin II impairs endothelial function via tyrosine phosphorylation of the endothelial nitric oxide synthase. J Exp Med 2009, 206: 2889-2896.

28 Ikeda Y, Aihar K, Yoshida S, Sato T, Yagi S, Iwase T, Sumitomo Y, Ise T, Ishikawa K, Azuma $\mathrm{H}$, Akaike M, Kato $\mathrm{S}$, Matsumoto T. Androgen-androgen receptor system protects against angiotensin II-induced vascular remodeling. Endocrinology 2009. 150: 2857-2864.

29 Sachse A, Wolf G. Angiotensin II-induced reactive oxygen species and the kidney. J Am Soc Nephrol 2007; 18: 2439-2446.

30 Jung O, Schreiber JG, Geiger H, Pedrazzini T, Busse R, Brandes RP. gp91 phoxcontaining NADPH oxidase mediates endothelial dysfunction in renovascular hypertension. Circulation 2004; 109: 1795-1801.

31 Kuo YH, Kuo LM, Chen CF. Four new C19 homolignans, schiarisanrins A, B, and D and cytotoxic schiarisanrin C, from Schizandra arisanensis. J Org Chem 1997; 62 3242-3245.

32 Chen YG, Qin GW, Xie YY, Cheng KF, Lin ZW, Sun HD, Kang YH, Han BH. Lignans from Kadsura angustifolia. J Asian Nat Prod Res 1998; 1: 125-131.

33 Zhang H, Schmeisser A, Garlichs CD, Plötze K, Damme U, Mügge A, Daniel WG. Angiotensin II-induced superoxide anion generation in human vascular endothelial cells: role of membrane-bound NADH-/NADPH-oxidases. Cardiovasc Res 1999; 44 215-222.

34 Lavigne MC, Malech HL, Holland SM, Leto TL. Genetic demonstration of p47phox dependent superoxide anion production in murine vascular smooth muscle cells. Circulation 2001; 104: 79-84.

35 Virdis A, Neves MF, Amiri F, Touyz RM, Schiffirn EL. Role of NAD(P)H oxidase on vascular alterations in angiotensin II-infused mice. J Hypertens 2004; 22: $535-542$.

(c)

This work is licensed under the Creative Commons Attribution-NonCommercial-No Derivative Works 3.0 Unported License. To view a copy of this license, visit http:// creativecommons.org/licenses/by-nc-nd/3.0/ 